\title{
HAVERÁ IMPORTAÇÃO DE MÃO DE OBRA NO BRASIL? UM ENSAIO SOBRE TRANSIÇÃO DEMOGRÁFICA, MERCADO DE TRABALHO E MIGRAÇÃ̃O
}

\section{Introdução}

Marden Barbosa de Campos

Cristiane Soares

A estrutura do mercado de trabalho brasileiro tem sido alterada significativamente nos últimos anos, tanto por aspectos de natureza demográfica quanto por modificações na composição educacional e inserção ocupacional dos trabalhadores. Um dos principais impactos provenientes dessas transformações relaciona-se à mudanças na oferta de trabalhadores jovens e de trabalhadores com baixa qualificação.

As projeções populacionais têm apontado para uma forte redução do total de jovens e um progressivo envelhecimento da estrutura etária da população do Brasil nas próximas décadas (IBGE, 2013). Estima-se que entre 2014 e em 2060, o número de indivíduos com entre 15 a 29 anos de idade irá diminuir em 35\%, enquanto entre os adultos com 30 a 44 anos de idade a redução será de 16\%. Vê-se que o processo de transição demográfica em curso terá impacto significativo sobre a estrutura do mercado de trabalho brasileiro. Além da redução da população em idade ativa, observa-se também um o crescimento da população não economicamente ativa, ou seja, um redução do nível de atividade da população.

Outro aspecto que tem modificado o perfil da mão de obra no Brasil é o aumento da escolaridade dos trabalhadores. Segundo os dados da Pesquisa Nacional por Amostragem de Domicílios - PNAD, nos últimos 10 anos o nível de instrução da população economicamente ativa aumentou significativamente, principalmente para a população com 12 anos ou mais de estudo, cujo volume quase dobrou entre 2003 e 2013, aumentando 96\% no período. A população com entre 9 e 11 anos de estudo, aumentou também cresceu muito no mesmo período, aumentando em $51 \%$. Destaca-se que esse avanço foi ainda mais acentuado para os jovens. Em 2003, cerca de metade da população de 16 e 29 anos tinha 9 anos ou mais de estudo. Após uma década, esse percentual passou para $71 \%$ dos jovens com essas idades. Este novo perfil educacional aponta para o fato de que, nas próximas décadas, o mercado sentirá os efeitos de uma oferta reduzida de trabalhadores menos qualificados. 
Dado que o Brasil possui um estrutura ocupacional que é bastante dependente de mão de obra abundante e pouco qualificada, um cenário que aponta para a redução do jovens, diminuição do nível de atividade e aumento da escolaridade inevitavelmente nos leva a questionar quem irá exercer, num futuro próximo, as profissões hoje ocupadas por jovens pouco qualificados.

O objetivo deste artigo é refletir sobre uma das possíveis soluções para o dilema acima colocado: o papel da migração internacional como solução para uma possível escassez de mão de obra no mercado de trabalho brasileiro. Países mais desenvolvidos lançaram mão dessa estratégia e tornaram-se, nas últimas décadas, regiões de atratividade para trabalhadores pouco qualificados, em grande parte nascidos nas regiões mais pobres do planeta. No Brasil, o crescimento da economia na segunda metade do século XX e as profundas desigualdades espaciais do território favoreceram o recrutamento de migrantes internos para suprir essa necessidade. Contudo, com a redução da disponibilidade de mão de obra desqualificada de forma abundante projetada para o próximos anos poderá ter um impacto significativo na atração de trabalhadores estrangeiros, fenômeno que já vem sendo observado, timidamente, em algumas regiões do País.

Embora saibamos que seja ainda um tanto precipitado tentar responder à da pergunta constante no título do artigo de forma definitiva, tentou-se seguir um caminho que nos deixe mais próximo da resposta, antevendo aproximação de questões emergentes para a sociedade em aspectos relacionados ao mercado de trabalho e à imigração internacional

\section{A transição demográfica e migração internacional}

A população brasileira vem passando por uma significativa transformação em sua composição etária, num fenômeno denominado de transição demográfica. Nesse processo, há a passagem de um regime com altas taxas de mortalidade e de fecundidade para outro regime em que ambas as taxas situam-se em níveis relativamente mais baixos. Essa é uma das principais transformações pelas quais vem passando a sociedade moderna, com implicações para diversos campos da vida individual, familiar e das sociedades envolvidas. Além de alterar as taxas de crescimento, a transição demográfica modifica sua a estrutura etária de modo a alterar a participação relativa de indivíduos 
com diferentes idades na população. Ou seja, há uma redistribuição na proporção de crianças, adultos e idosos na população.

No Brasil, os níveis e padrões de mortalidade e fecundidade de todas as regiões modificaram-se de forma considerável nas últimas décadas. O formato típico de uma "pirâmide" populacional - com uma base larga representada pelo elevado número de crianças - vem dando lugar à uma estrutura de população envelhecida, cuja base vai tornando-se cada vez mais estreita e topo cada vez mais largo, pelo aumento contínuo da proporção de idosos.

Aliado a esse processo, nos últimos 50 anos a migração internacional ressurgiu com um fenômeno intenso e de alcance global. Em grande parte, ela foi direcionada a suprir a oferta de mão de obra ocasionada pelo envelhecimento demográfico e a restrição de mão de obra disponível em países cujo processo de transição demográfica encontrava-se numa etapa avançada, como no caso dos regiões mais desenvolvidos

Em sociedades tradicionalmente receptoras de população, como Austrália, Canadá e Estados Unidos, a intensidade da imigração aumentou, sendo que a origem dos migrantes alterou-se da Europa, principal origem de migrantes do passado, para países da Ásia, África e América Latina. Ao mesmo tempo, na Europa, países que eram tradicionais regiões de origem de migrantes, como Portugal, Espanha e Itália, também tornaram-se importantes receptores de população das regiões de suas ex-colônias. O Japão, que vivia uma baixíssima taxa de crescimento demográfico e um rápido envelhecimento populacional, também começou a receber um volume crescente de imigrantes da Ásia e da América Latina (MASSEY et. All., 1998). O Brasil inseriu-se nesse processo, principalmente a partir da década de 1980, como uma região de emigração para Estados Unidos, Oeste Europeu e também para o Japão.

Embora tenha experimentado, pela primeira vez em sua história, uma perda de população para o resto do mundo nas últimas décadas do século passado, o Brasil começa a receber nos últimos anos um fluxo de imigrantes de outros países, justamente no memento em que há um envelhecimento demográfico acelerado de sua população. Contudo, ensaios que tratam especificamente dessa relação ainda não foram realizados no Pais e, desse modo, ainda não conhecemos os mecanismos que possam conectar os dois processos. 
Diversos trabalhos têm destacado o aumento de estrangeiros vivendo no País. Afirma-se isso apontando para o aumento do número de naturais dos países do Cone Sul vivendo no Brasil (SALA; CARVALHO, 2008), assim como a intensificação da migração de bolivianos (SILVA, 2006), de africanos e de asiáticos (BAENINGER; LEONCY, 2001). Nos últimos anos, as migrações de bolivianos e haitianos vem ganhando destaque crescente, tanto dos estudiosos do tema como da mídia em geral, como demonstram os trabalhos de Baeninger (2012), Godoy (2011) e Fazito (2008). Esses autores também mostram que há um aumento da atratividade da Região Nordeste em relação a imigrantes europeus e o incremento das trocas migratórias entre Brasil, Paraguai, Uruguai e Argentina, ultimamente favoráveis ao Brasil.

\section{Migração e mercado de trabalho: o dualismo econômico}

Uma das principais abordagens teóricas utilizadas para a migração à alterações na estrutura do mercado de trabalho é a que trata da dualidade do mercado de trabalho das economias mais desenvolvidas. Essa abordagem postula que os fluxos migratórios seriam uma resposta as demandas intrínsecas do mercado de trabalho das economias industriais modernas, dada a evolução desse mercado para uma estrutura dual, bifurcado em dois setores. Por isso, são chamadas de teorias do mercado de trabalho dual ${ }^{1}$.

Segundo esta abordagem, a economia se divide em dois setores: 1) setor primário intensivo em capital, que emprega trabalhadores qualificados, onde há uma estabilidade dos empregos e boa estrutura de trabalho; 2) setor secundário - intensivo em trabalho, que emprega trabalhadores pouco qualificados e com trabalhos precários (MASSEY, 1993). Dessa forma, o dualismo existente entre capital e trabalho extrapolaria para a força de trabalho, segmentando a estrutura do mercado.

Os baixos salários, as condições instáveis de empregabilidade e a falta de perspectivas profissionais presentes no setor secundário tornam essas profissões pouco atrativas para, no caso dos países desenvolvidos, a população local. Logo, uma solução para suprir a demanda por esse tipo de mão de obra é o recrutamento de trabalhadores estrangeiros.

Setores intensivos em capital, geralmente possuem empregos estáveis, com trabalhadores qualificados que recebem investimentos especializados em treinamento e educação. Os empregos são complexos e requerem considerável conhecimento e

\footnotetext{
${ }^{1}$ Para uma ampla revisão teórica dessa abordagem, ver PIORE (1972).
} 
experiência, gerando acumulação de capital humano. Estes trabalhadores tendem a ser altamente profissionalizados e protegidos por instituições e conselhos profissionais, com contratos rígidos que dividem o custo de demissão com os empregadores. Isso faz com que os empregados tornam-se cada vez mais caros, parecendo-se mais com o próprio capital. No setor secundário, por sua vez, os trabalhadores, possuem contratos mais instáveis ou mesmo trabalham na informalidade, arcando quase completamente com os custos de sua demissão. Não há incentivo para os empregadores manterem esses empregos em períodos de baixa demanda, pois pouco investimento é feito nestes trabalhadores.

O que os empregadores necessitam é que os trabalhadores vejam os trabalhos pouco qualificados apenas como uma maneira de ganhar dinheiro, sem nenhuma implicação para status pessoal ou prestígio. No passado, os empregos menos qualificados eram supridos, prioritariamente, por jovens e mulheres. Contudo, o avanço do processo de transição demográfica, a mudança de papeis da mulher na sociedade e a escolarização da população fazem com que haja uma escassez de indivíduos dispostos a aceitar trabalhos entre a população local. Esses cargos passaram a ser ocupados então, nas últimas décadas, pelos trabalhadores imigrantes. Em geral, eles buscam alguma fonte de renda ou acumulação de habilidades visando um objetivo específico como, por exemplo, comprar terreno, pagar uma faculdade, construir uma casa, ou envolvidos numa estratégia familiar, como é o caso do envio de remessas. Como o grupo de referência social do migrante é a sociedade da região de origem, o fato de estar esforçando-se para buscar recursos com a migração, inclusive enviando remessas para a família, contribui mais para aumentar seu status na origem do que uma avaliação do tipo de tarefa realizado no exterior ou região de residência atual.

Embora essa perspectiva tenha sido utilizada prioritariamente em análises de migração internacional, ela é perfeitamente aplicável à migração interna que ocorre entre diferentes regiões de um mesmo país.

\section{Dinâmica do mercado de trabalho brasileiro entre 2000 e 2010}

Nos últimos anos, o mercado de trabalho brasileiro tem passado por mudanças estruturais importantes, como o crescimento da geração de emprego, o aumento da taxa de formalização, a redução do desemprego, a expansão da renda do trabalho e a 
evolução real do salário mínimo, o que reflete um cenário diferente do observado na década de 1990 (DEDECCA, 2005). Esses avanços têm ocorrido em paralelo com um processo de transição demográfica, amplificando as transformações do mercado de trabalho.

No que se refere à distribuição da população em idade ativa dentro e fora da força de trabalho, os indicadores mostram que o crescimento da população economicamente ativa (PEA) tem sido inferior ao crescimento da população em idade ativa (PIA), o que acarreta em uma ampliação da população não economicamente ativa no período. Dados sobre o perfil da população não economicamente ativa (NPEA) têm mostrado que cerca de $68 \%$ dela é composta por mulheres e que um em cada quatro pessoas da NPEA tem idade entre 16 a 24 anos (SÍNTESE..., 2014).

O aumento da escolarização da população jovem e o crescimento da renda média familiar tem ajudado a explicar o crescimento da população não economicamente ativa. Considera-se que muitos jovens têm postergado a entrada no mercado de trabalho para investir na formação educacional. Com o crescimento da renda, os grupos localizados "à margem" da ocupação, reconhecidamente as mulheres e os jovens, tendem a ter menor inserção na força de trabalho.

\section{Gráfico 1}

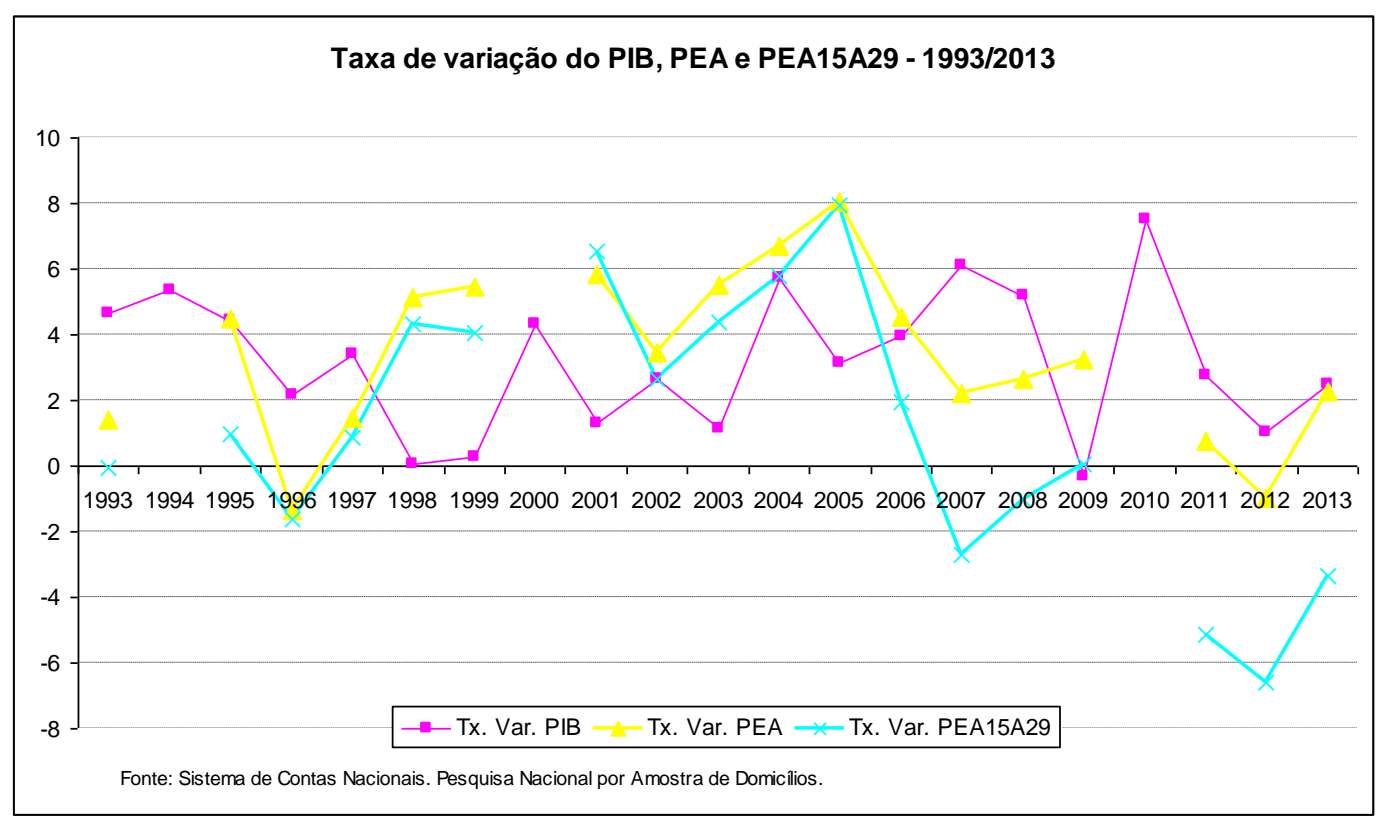

O Gráfico 1 mostra a dinâmica da população economicamente ativa total e de 15 a 29 anos de idade nos últimos 20 anos, face ao comportamento do PIB. Observa-se que a atividade dos jovens tem seguido o padrão da PEA total; no entanto, desde 2005, a 
redução da PEA neste grupo etário tem sido consideravelmente maior na comparação com a população total. Além disso, o comportamento da PEA, em geral, tem se mostrado contra-cíclico à variação do PIB, com exceção nos últimos três anos. A partir deste cenário, é possível inferir que fatores econômicos pouco têm influenciado a dinâmica da PEA, ou seja, que o crescimento da economia não tem atuado como um incentivo para a inserção dos jovens no mercado de trabalho.

\section{Migração interna e mercado de trabalho: o Censo Demográfico 2010}

A análise dos dados do Censo Demográfico mostra que, no Brasil, do total das 141 milhões de pessoas que possuem 16 anos ou mais de idade, 62 milhões residem em um município daquele em que nasceram, representando 44\% do total. Destes, 25 milhões de pessoas, ou $40 \%$ dos não naturais do município de residência, nasceram em outra Unidade da Federação (UF).

O nível de ocupação dos não-naturais da UF foi de $61,8 \%$. Verificou-se que $48 \%$ dos não-naturais da UF eram empregados com carteira, percentual acima do observado para o conjunto de trabalhadores de 16 anos ou mais de idade. No que se refere aos setores de atividade em que trabalhavam, o setor de serviços domésticos foi o que mais empregou trabalhadores nascidos em outros estados. Em seguida, vieram os setores de lavoura, construção e comércio.

O perfil educacional dos não-naturais da UF indicou que 49,3\% deles não tinham instrução ou possuíam apenas o ensino fundamental incompleto; outros 16,7\% tinham apenas o ensino fundamental completo ou nível médio incompleto. Logo, vemos que 66\% dos não-naturais da UF não tinham concluído o nível médio. No caso dos nãonaturais ocupados, este percentual é um pouco menor $(59,6 \%)$, mas ainda assim vemos que mais da metade desse trabalhadores não tinham o nível médio.

Quando analisada a distribuição dos não-naturais ocupados segundo o grupamento ocupacional, observou-se que a maioria deles estava em ocupações de menor qualificação $(58,9 \%)$. Sendo que parcela expressiva (21\%) estava em ocupações elementares, grupamento que inclui trabalhadores domésticos, ambulantes, ajudantes na preparação de alimentos, coletores de lixo, entre outros trabalhadores elementares na agropecuária, mineração, construção, indústria de transformação. No caso da categoria 
de ocupações elementares, do total de 16,9 milhões de ocupados nesta categoria, 3,3 milhões, isto é, $19 \%$ eram não-naturais da UF.

Além dos não-naturais da UF, também foram analisados aqueles que, segundo o Censo Demográfico 2010, residiam há menos de 10 anos na Unidade da Federação (migrantes de última etapa), visando a inserção econômica de migrantes recentes, contabilizavam 7,4 milhões indivíduos.

Parcela significativa dos migrantes de última etapa (46\%) tem idade inferior a 30 anos e outra parcela, um pouco menor, tem entre 30 e 49 anos de idade (39\%). Logo, eles podem ser caracterizados como uma população jovem.

Com relação às ocupações exercidas por este grupo de migrantes, 58,8\% deles estavam em ocupações que exigem baixa ou média qualificação, praticamente o mesmo percentual do conjunto de não-naturais da UF.

Os setores de atividade com os maiores percentuais de migrantes de última etapa foram serviços domésticos, atividades mal definidas, construção, serviços especializados, atividades de comércio não especificadas e atividades de restaurante. Esta ordenação difere da encontrada para os não-naturais da UF em alguns aspectos: o primeiro é que a atividade de lavoura não aparece entre os migrantes recentes, embora esteja na quarta posição para os não-naturais; outro se refere às posições na hierarquia dos setores de construção e de serviços especializados que entre os migrantes mais recentes assume a terceira e quarta posição, respectivamente, e no caso dos não-naturais da UF assume a quinta e a terceira posição, respectivamente.. O que não se modificou foi a posição dos serviços domésticos, que segue como o principal setor de atividades para os migrantes de última etapa.

Os jovens migrantes de última etapa, com entre 16 a 29 anos de idade, correspondiam a 5,7 milhões de pessoas, sendo que 65\% deles trabalhavam na data do Censo. Dos 3,7 milhões de jovens ocupados, 59,3\% eram empregados com carteira assinada, percentual superior ao verificado para o conjunto de não-naturais da UF (48\%).

Os jovens migrantes concentravam-se no serviço doméstico $(6,4 \%)$, comércio de produtos alimentícios (4,2\%), atividades de construção não especificada (4,0\%) e restaurante (3,9\%). Estes são os mesmos setores observados para os não-naturais da UF, invertendo apenas a posição entre os setores de agricultura e construção. Quando analisados os dados por ocupação, pode-se constatar que um percentual mais elevado 
desses jovens estava ocupado em trabalhos de baixa ou média qualificação $(65,8 \%)$. Somente $22,4 \%$ trabalhavam em ocupações elementares e $20 \%$ ou nos serviços ou como vendedores no comércio.

Com base nesses dados, vê-se que grande parte das ocupações menos qualificadas no Brasil vem sendo, ainda hoje, ocupadas por imigrantes internos, principalmente entre a população mais jovem.

\section{Migração internacional: um incremento para a força de trabalho no Brasil?}

Embora o objetivo do presente artigo seja fazer considerações sobre o comportamento futuro das migrações internacionais no Brasil, não há como avançar em hipóteses prospectivas para a migração sem considerar a situação atual do fenômeno. Nesse sentido, a presente seção analisa a inserção ocupacional dos estrangeiros no País, com base no Censo Demográfico de 2010 e no Sistema de Registros de Estrangeiros da Polícia Federal. Sabemos que as análises baseadas nesses tipo de informação não permitem abarcar a totalidade do fenômeno migratório, dada a dificuldade de produzir registros sobre imigrantes irregulares, indocumentados ou com situação de permanência indefinida. De todo modo, a amplitude de informações disponíveis nessas bases permite conhecer a situação laboral de um contingente significativo de estrangeiros que vivem no País.

Segundo o Censo Demográfico, em 2010, havia 534 mil estrangeiros de 16 anos ou mais de idade no Brasil. O percentual de jovens entre os estrangeiros era bastante reduzido, visto que 13,6\% tinham de 16 a 29 anos de idade em 2010, enquanto 38,7\% tinham 65 anos ou mais de idade.

A participação dos estrangeiros no mercado de trabalho era bastante reduzida em 2010, visto que somente $51 \%$ deles eram economicamente ativos. Isso decorre do fato de que grande parte dos estrangeiros captados pelo Censo eram indivíduos com idade avançada, conforme explicitado, que aqui chegaram há décadas e que já haviam se desligado da atividade econômica rotineira.

Os estrangeiros ocupados contabilizavam 263,4 mil pessoas e a maioria deles trabalhava como conta-própria $(38,5 \%)$. A segunda categoria que concentrava grande parte dos estrangeiros era a de empregados sem carteira (29,4\%). Acerca da atividade e ocupação exercida, os resultados indicaram que os estrangeiros ocupados estavam concentrados 
em oito setores de atividade: comércio (21,4\%), educação $(7,1 \%)$, confecção de artigos de vestuário (6,9\%), agricultura e pecuária $(4,8 \%)$, saúde $(4,5 \%)$, alimentação $(4,5 \%)$, construção $(3,8 \%)$ e administração pública $(2,2 \%)$. As mulheres apresentaram um percentual maior que o dos homens somente no setor de educação $(50,5 \%)$, mas não há um setor específico de predominância das mulheres estrangeiras no mercado de trabalho (Tabela 1).

Tabela 1

Estrangeiros de 16 anos ou mais de idade ocupados segundo os principais setores de atividade, por sexo - 2010

\begin{tabular}{|c|c|c|c|c|c|c|}
\hline Principais setores de atividade & \multicolumn{3}{|c|}{ Total } & \multicolumn{3}{|c|}{ Proporção e distribuição percentual } \\
\hline Setores de Atividade & Total & Homens & Mulheres & Total & Homens & Mulheres \\
\hline $\begin{array}{lllll}\begin{array}{l}\text { Agricultura, } \\
\text { relacionados }\end{array} & \text { pecuária, caça } & \text { e } & \text { serviços } \\
\end{array}$ & 12.541 & 9.368 & 3.173 & 4,8 & 74,7 & 25,3 \\
\hline Confecção de artigos do vestuário e acessórios & 18.263 & 9.614 & 8.649 & 6,9 & 52,6 & 47,4 \\
\hline Serviços especializados para construção & 9.905 & 9.142 & 762 & 3,8 & 92,3 & 7,7 \\
\hline $\begin{array}{l}\text { Comércio, exceto de veiculos automotores e } \\
\text { motocicletas }\end{array}$ & 56.378 & 38.827 & 17.551 & 21,4 & 68,9 & 31,1 \\
\hline Alimentação & 11.821 & 7.661 & 4.160 & 4,5 & 64,8 & 35,2 \\
\hline Administração pública, defesa e seguridade social & 5.926 & 3.392 & 2.534 & 2,2 & 57,2 & 42,8 \\
\hline Educação & 18.749 & 9.285 & 9.463 & 7,1 & 49,5 & 50,5 \\
\hline Atividades de atenção à saúde humana & 11.895 & 6.060 & 5.835 & 4,5 & 50,9 & 49,1 \\
\hline
\end{tabular}

Fonte: IBGE, Censo Demográfico 2010 .

Já com relação à ocupação, o grupamento com o maior percentual de estrangeiros é o de profissionais das ciências e intelectuais $(23,6 \%)$, seguido dos trabalhadores dos serviços e comércio (16,9\%). Outro grupo com percentual elevado é o de diretores e gerentes $(12,6 \%)$. Logo, é possível afirmar a partir do perfil ocupacional dos estrangeiros no País, com base no Censo Demográfico, é de profissionais exercendo ocupações qualificadas (Tabela 2).

Tabela 2

Estrangeiros de 16 anos ou mais de idade ocupados segundo os grupamentos de ocupação, por sexo - 2010

\begin{tabular}{|c|c|c|c|c|c|c|}
\hline \multirow{2}{*}{ Ocupações } & \multicolumn{3}{|c|}{ Total } & \multicolumn{3}{|c|}{ Proporção } \\
\hline & Total & Homens & Mulheres & Total & Homens & Mulheres \\
\hline Total & 263.421 & 174.182 & 89.239 & 100 & 100 & 100 \\
\hline $\begin{array}{l}\text { Membros das forças armadas, policiais e } \\
\text { bombeiros militares }\end{array}$ & 271 & 237 & 34 & 0,1 & 0,1 & 0,0 \\
\hline Diretores e gerentes & 33.096 & 25.377 & 7.719 & 12,6 & 14,6 & 8,6 \\
\hline Profissionais das ciências e intelectuais & 62.099 & 39.972 & 22.128 & 23,6 & 22,9 & 24,8 \\
\hline Técnicos e profissionais de nível médio & 19.114 & 13.847 & 5.267 & 7,3 & 7,9 & 5,9 \\
\hline Trabalhadores de apoio administrativo & 8.207 & 3.422 & 4.785 & 3,1 & 2,0 & 5,4 \\
\hline $\begin{array}{l}\text { Trabalhadores dos serviços, vendedores dos } \\
\text { comércios e mercados }\end{array}$ & 44.457 & 27.565 & 16.893 & 16,9 & 15,8 & 18,9 \\
\hline $\begin{array}{l}\text { Trabalhadores qualificados da agropecuária, } \\
\text { florestais, da caça e da pesca }\end{array}$ & 8.140 & 5.995 & 2.145 & 3,1 & 3,4 & 2,4 \\
\hline $\begin{array}{l}\text { Trabalhadores qualificados, operários e } \\
\text { artesãos da construção, das artes mecânicas e } \\
\text { outros ofícios }\end{array}$ & 18.635 & 15.885 & 2.750 & 7,1 & 9,1 & 3,1 \\
\hline $\begin{array}{l}\text { Operadores de instalações e máquinas e } \\
\text { montadores }\end{array}$ & 22.933 & 14.208 & 8.725 & 8,7 & 8,2 & 9,8 \\
\hline Ocupações elementares & 18.573 & 9.631 & 8.942 & 7,1 & 5,5 & 10,0 \\
\hline Ocupações mal definidas & 27.894 & 18.043 & 9.852 & 10,6 & 10,4 & 11,0 \\
\hline
\end{tabular}


Os números registrados na base de dados do Sistema Nacional de Registros de Estrangeiros - SINCRE do Departamento da Polícia Federal, entre 2000 e 2014 corroboram os indicadores obtidos a partir do Censo Demográfico 2010. Em 2014, o setor de imigração da Polícia Federal contabilizou 273,3 mil estrangeiros de 15 anos ou mais de idade no País (Tabela 3).

A interpretação da base de dados não é trivial, dado que não há rigor estatístico acerca do preenchimento das informações, dado que se prestam a outros fins do que a análise de dados agregados. Nesse sentido, há problemas com as informações sobre a profissão do imigrante. Do total de 273,3 mil imigrantes, cerca de 31,6\% não tinham profissão ou eram inativos (estudante, aposentado, dependente, menor, bolsista, militar na inatividade). Para aqueles que declaram alguma profissão (187 mil), 54\% tinham mais de 36 anos de idade, sendo que 53,1\% tinham uma profissão com qualificação superior.

Tabela 3

Estrangeiros de 15 anos ou mais de idade, residentes no Brasil, por grupos de idade segundo a condição de atividade, total e proporção 2014

\begin{tabular}{|c|c|c|c|}
\hline \multirow{2}{*}{ Condição de atividade } & \multirow{2}{*}{ Total } & \multicolumn{2}{|c|}{ Grupos de idade } \\
\hline & & 15 a 36 anos & 37 ou mais \\
\hline \multicolumn{4}{|c|}{ Total } \\
\hline Total & 273.370 & 126.184 & 147.186 \\
\hline Inativo & 24.327 & 8.673 & 15.654 \\
\hline Sem profissão & 62.063 & 47.006 & 15.057 \\
\hline Com profissão & 186.980 & 70.505 & 116.475 \\
\hline Superior & 99.340 & 26.331 & 73.009 \\
\hline Médio & 9.655 & 3.732 & 5.923 \\
\hline Inferior & 77.985 & 40.442 & 37.543 \\
\hline \multicolumn{4}{|c|}{ Proporção } \\
\hline Total & 100 & 100 & 100 \\
\hline Inativo & 8,9 & 6,9 & $\overline{10,6}$ \\
\hline Sem profissão & 22,7 & 37,3 & 10,2 \\
\hline Com profissão & 68,4 & 55,9 & 79,1 \\
\hline Superior & 53,1 & 37,3 & 62,7 \\
\hline Médio & 5,2 & 5,3 & 5,1 \\
\hline Inferior & 41,7 & 57,4 & 32,2 \\
\hline
\end{tabular}

Fonte: Polícia Federal, Coordenação Geral de Polícia de Imigração.

As 10 categorias de "profissões" listadas com os maiores contingentes de estrangeiros segundo o SINCRE foram: 1) estudante, 2) diretor e gerente, 3) outra não classificada, 4) decorador, 5) oficial, 6) prendas doméstica, 7) arquiteto, 8) sacerdote, 9) vendedor e 10) aposentado. Excluídos os inativos, como estudantes e aposentados, a principal categoria profissional foi diretores e gerentes (24,7 mil). Este grupo constitui uma mão de obra qualificada, assim como aqueles denominados como "oficiais", que quarta principal categoria. A segunda categoria corresponde a "outras ocupações", um grupo 
heterogêneo de origem em vários países que não permite inferir acerca do trabalho realizado. A terceira categoria com maior contingente de estrangeiros foi o de “decorador", composta por bolivianos jovens com entre 20 e 29 anos de idade.

Conforme ressaltado, sabemos que os registros captados por ambas as fontes analisadas tentem a ter uma cobertura maior entre os estrangeiros com situação de permanência definitiva no País, grande parte deles com elevada qualificação. De todo modo, a parcela de estrangeiros inseridos em ocupações de maior qualificação no mercado de trabalho brasileiros não é desprezível e traz informações importantes sobre a realidade migratória atual.

\section{Considerações Finais}

O presente estudo procurou discutir algumas questões acerca das mudanças no mercado de trabalho brasileiro, tendo como pano de fundo o processo de transição demográfica, o avanço da escolaridade, o aumento da população não economicamente ativa e o papel das migrações internas e internacionais no suprimento da demanda por mão de obra no País.

Embora a escassez de mão de obra nas regiões mais desenvolvidas seja historicamente suprida com a imigração interna, notadamente de pessoas pouco qualificadas, as evidências apresentadas indicam que a disponibilidade desse tipo de trabalhadores irá reduzir-se bruscamente nas próximas décadas. É necessário refletir sobre as formas de suprimento dessa demanda, e o presente trabalho dedicou-se a discutir uma das alternativas disponíveis para tal: o recrutamento de mão de obra estrangeira.

Essa análise teve como referência conceitual a teoria do mercado de trabalho dual, buscando entender se uma possível escassez de mão de obra poderia restringir-se a setores específicos do mercado de trabalho, para o qual seriam recrutados imigrantes internacionais. Embora a teoria explique o recrutamento de mão de obra pouco qualificada em países mais desenvolvidos, no Brasil ela parece apontar para a direção oposta, em que a imigração internacional estaria suprindo uma escassez de mão de obra qualificada.

Evidências indicam, embora não quantifiquem, que uma parcela considerável dos estrangeiros que residem no Brasil insere-se em ocupações pouco qualificadas, diferente do que foi apontado no presente estudo. É o caso, por exemplo, do que acontece com os 
haitianos e com alguns grupos de trabalhadores sulamericanos. Considerando essa perspectiva, poder-se-ia expandir a aplicação da teoria do mercado dual não apenas para a estrutura do mercado de trabalho, mas para a composição da própria migração. Nesse sentido, vemos que que os fluxos populacionais que se encaminham para o País atualmente estariam divididos em dois grupos de trabalhadores distintos, cada um dirigido a suprir uma parcela específica do mercado de trabalho, com qualificação exigida bem diferente.

Resta a dúvida do que irá ocorrer com algumas ocupações específicas de trabalhadores com baixa qualificação que hoje são supridas pela migração interna e que são problemáticas para o recrutamento de trabalhadores estrangeiros, como no caso do trabalho doméstico remunerado, nas funções de empregadas domésticas, babás e cuidadoras, que muitas vezes residem nos domicílios em que trabalham. Haverá uma aceitação de estrangeiros ou estrangeiras realizando a mesma atividade, serão criadas atividades substitutas para essas funções, elas desaparecerão ou sofreram uma alta considerável dos salários?

As formulações do presente trabalho baseiam-se em tendências recentes e não consolidadas e, desse modo, são provisórias e abertas a contestação. Assim como ocorre com outros fenômenos sociais, é impossível fazer previsões seguras quanto ao comportamento futuro das migrações. Entretanto, as evidências atuais são os dados que temos em mãos e nada garante que no futuro os fluxos migratórios modifiquem-se completamente. Talvez, a preocupação maior deva ser dirigida à parcela do fenômeno não coberta pelas bases de dados utilizadas.

De todo modo, a forma diferenciada que como o Brasil vem inserindo-se nos sistemas de migração internacional inviabiliza a aplicação de modelos teóricos desenvolvidos em contexto que pouco tem a ver com a situação do País. 


\section{Referências}

BAENINGER, R. Imigração Boliviana no Brasil / Rosana Baeninger (Org.). Campinas: Núcleo de Estudos de População-Nepo/Unicamp; Fapesp; CNPq; Unfpa, 2012.

BAENINGER, R.; LEONCY, C. Perfil dos estrangeiros no Brasil segundo autorizações de trabalho (Ministério do Trabalho e Emprego) e registros de entradas e saídas da Polícia Federal (Ministério da Justiça). In: CASTRO, Mary Garcia: Migrações internacionais:contribuições para políticas. Brasília: Comissão Nacional de População e Desenvolvimento, p.187-242, 2001.

DEDECCA, C. S. (2005) Notas sobre a Evolução do Mercado de Trabalho no Brasil. Revista de Economia Política, vol. 25, no 1 (97), pp. 94-111, janeiro-março/2005.

DIEESE (2011). Qualificação Profissional e Mercado de Trabalho: Reflexões e ensaios metodológicos construídos a partir da Pesquisa de Emprego e Desemprego

FAZITO, D. Situação das migrações internacionais do Brasil contemporâneo. In: Populações e políticas sociais no Brasil: os desafios da transição demográfica e das migrações internacionais. Brasília: Centro de Gestão e Estudos Estratégicos, 2008.

GODOY, G. G. O caso dos haitianos no Brasil e a via da proteção humanitária complementar. In: RAMOS, A. C., RODRIGUES, G. e ALMEIDA, G. A. (orgs.). 60 anos de ACNUR: perspectivas de futuro. São Paulo: CL-A Cultural, 2011.

INSTITUTO BRASILEIRO DE GEOGRAFIA E ESTATÍSTICA. Censo Demográfico 2010. Rio de Janeiro: IBGE, 2010.

INSTITUTO BRASILEIRO DE GEOGRAFIA E ESTATÍSTICA. Projeção da população do Brasil por sexo e idade 2000-2060; Projeção da população das Unidades da Federação por sexo e idade 2000-2030. Rio de Janeiro: IBGE, 2013.

INSTITUTO BRASILEIRO DE GEOGRAFIA E ESTATÍSTICA. Síntese de Indicadores Sociais: uma análise das condições de vida da população brasileira 2014. Rio de Janeiro: IBGE, 2014.

MASSEY et. All. Theories of international migration: A review and appraisal. Population and Development Review 19:431-66, 1993.

MASSEY et. All. Worlds in motion: Understanding international migration at the end of the millennium. Oxford:Clarendon Press, 1998.

PIORE, M.J. The Dual Labor Market: Theory and Implications. In: Gordon, David M. Theories of Poverty and Underemployment. Lexington, MA: D.C. Heath and Company, 1972.

SALA, G. A.; CARVALHO, J. A. M. de. A presença de imigrantes de países do Cone Sul no Brasil: medidas e reflexões. Revista Brasileira de Estudos de População, Rio de Janeiro: ABEP, v.25, n.2, p.287-304, jul./dez. 2008.

SILVA, S. A. da. Bolivianos em São Paulo: entre o sonho e a realidade. Estudos Avançados, São Paulo: USP/IEA, v.20, n.57, p.157-170, maio/ago. 2006. 